\title{
Theoretical Foundations of Latent Aging and Imitation of Aging
}

\author{
Fahri Ozsungur* \\ Doctor of Philosophy in Family and Consumer Sciences, Turkey
}

*Corresponding author: Adana Chamber of Commerce / Hacettepe Univ. Doctor of Philosophy in Family and Consumer Sciences, Turkey.

Received Date: February 07, 2020

Published Date: February 21, 2020

\begin{abstract}
s
In this study, the theoretical foundations of latent aging and imitation of aging were presented with the systematic review method. differences between motivation model, external motivation, intrinsic motivation, the relationship between extrinsic and intrinsic motivation, perceived behavior control, socio-emotional fallacy theory, latent aging, imitation of aging, latent aging and imitation of aging were revealed with this study. Discussion and suggestions were included at the end of the study.
\end{abstract}

\section{Introduction}

Aging is an important phenomenon experienced by humanity [1]. The increasingly elderly population has increased aging studies $[2,3]$. Advances in technology and medicine cause improvements in individuals' health. These improvements prolong life and reduce the average age of death [4]. However, the diseases and psychological factors that emerged due to the immune system started to affect the individual's perception of aging [5,6]. Despite advances in medicine, psychological problems that arise due to joint and muscle aches and the necessity of continuous treatment due to health problems negatively affect the psychological resilience of individuals [7]. Despite these developments, there is not enough research on these issues in the literature.

This study aims to introduce latent aging, imitation of aging, which develops under the influence of an autoimmune or palliative disease, to the literature. Moreover, it is to provide some predictions for future studies by revealing the similarities and differences between these new types of aging. The study is thought to make important contributions to the fields of neuropsychology, psychology, immunology, rheumatology, gerontology, and aging. This study was prepared by the systematic review method, and the subject title was created by the literature review.

\section{Theoretical Framework}

\section{Motive}

Motive is a force that shapes the decision-making behaviors of people and ensures their continuity [8]. Control and direction of behavior are possible with motives [9]. Latent aging, an important output of the perceptual process, is significantly affected by motives.

\section{Motivation model}

First degree motives are unlearned and psychological based motives [10]. Second-degree motives are motives that are not affected by the instinctive and biological need factors of individuals, can be influenced by consumers' preferences, may be influenced by external or internal factors, and may lead to the development of reflection and counter-behavior $[10,11]$. Although it takes its source from instinctive behavior, it is possible to talk about the existence of second-degree motives in almost every situation where there is a choice. Many factors such as fame, social status, the purchasing power of money, heroism, leadership, success, failure, stress, sadness, pessimism point to the existence of secondary motives [12]. Motives explained under the motivational model are divided into two as internal and external. 


\section{External/Extrinsic motivation}

It is the desire to conduct an activity to achieve positive results such as external motivation, reward or incentive, or to avoid negative consequences such as punishment or exclusion [13]. Extrinsic motivation, which has important effects on behavior, has been researched especially in the context of its effects on performance in the business field. Porter and Lawler [14], using Vroom's [15] expectation theory, found that internal and external motivation positively influenced job performance and employee well-being. The determination of Stajkovic and Luthans [16] regarding the determination that spiritual and material incentives have a synergistic effect on performance also confirms this situation. Extrinsic motivation exists with important effects such as social acceptance, joining the group, being in a team, and transitioning to social classes. These effects also play a role in the development of important behavior patterns such as consumption [17].

\section{Internal/intrinsic motivation}

Carrying out activities for internal satisfaction means internal motivation. Intrinsic motivations include giving importance to feelings of inner satisfaction such as personal pleasure, entertainment, and interest against external factors and pressures [18]. The intrinsicness of motivation is related to the individual's level of autonomy, self-confidence, and competence. Individuals whose autonomy and competence are supported are more likely to develop their internal motivation [19]. Intrinsic motivation, where pleasure and satisfaction are at the forefront, reveals that the tendency of the individual to realize his inner impulses despite external factors is a major factor in the development of behaviors [20].

\section{The relationship between external and internal motivation}

Intrinsic motivation affects individual health, positive behavior, and well-being [21]. These two types of motivation, whose independent positive contributions were determined in terms of their effects on performance, are different concerning each other. One factor that promotes one of these two types of motivation with a negative relationship between them may weaken the other [22]. The effects of both motivations in achieving the same behavior turn into an important conflict and a race of utility. On the one hand, external effects such as rewarding or facing punishment, on the other hand, feelings of individual pleasure and inner satisfaction force one to direct only one of these motives, either completely or predominantly [23].

\section{Perceived behavioral control}

Ajzen and Driver [24] have suggested that the more positive an individual's attitude towards behavior and subjective norms are, and the greater the perceived behavioral control, the intention to fulfill that behavior should be stronger. When individuals believe that they lack resources and have little control over performing a behavior, their intention to perform behavior may be low even if it is under the influence of a positive attitude and/or positive subjective norms [25].

\section{Socio-emotional fallacy theory}

The perception of time and age varies according to individuals. This change is shaped according to the psychological, medical, social and physical conditions of the individual [26]. The self-confidence and belief in the life of the individual under the influence of the disease may decrease [27]. Continuing the disease and combating severe pain can cause psychological fatigue/exhaustion. This is especially common in palliative and rheumatology patients [28]. An individual who has been exposed to mobbing and stress at work, a woman who has been subjected to violence and sexual abuse, may experience loss of emotional regulation about the events they encounter. The perception of the individual is under the influence of these events, which are put under heavy pressure rather than the emotion to be arranged according to the incident. With the development of complex emotions, symptoms of psychological breakdown and depression are observed. Thus, the individual codes the events he perceives under normal conditions according to the weight of the current conditions, not age or time. Emotional choices are made by going beyond the information gained while the codings are placed in memory. The negative emotions caused by the continuous disease state may affect perception and cause misconceptions.

Continuity of external factors, diseases that cause psychological fatigue, can cause the individual to perceive the facts differently than normal [29]. Especially the emotional and psychological effects of social events on the individual affect perception significantly. Some decline in the old age process can cause perceptual errors. These perceptual errors can reveal latent aging.

\section{Latent aging}

Latent aging is a perceptual and behavioral condition that occurs when individuals transform the events occurring in the external environment into the perception of aging in the cognitive process and adopt this idea [30]. Individuals associate and internalize their experiences with the aging of older individuals around them. This internalization causes the perception of aging.

Latent aging occurs in two ways: a) Lack of perceptual management (associating events around the individual with aging), b) Neuropsychological effects. The emergence of the menopause period above a certain age and the appearance of Alzheimer's and Parkinson's diseases with aging causes the perception of aging [31]. Diseases occurring in old age, physical declines, anxiety, depression, and neuropsychological functional problems create the perception of aging in the individual [32].

Problems in the psychosocial context can lead to behavioral disorders, reasoning difficulties, and emotional problems [33]. This situation may be caused by a possible problem in the prefrontal cortex. Therefore, it is possible to determine clinically whether the individual is exposed to latent aging or not by neuropsychological 
evaluation. Besides, when the individual experiences the events in his / her environment, s/he starts to feel old and this may cause the frontal lobe paradox [34]. It is an important problem that an individual who has no reasoning power and cognitive level cannot reflect his behaviors to active life. This condition can prevent active aging. Latent aging is a result of these symptoms.

\section{Imitation of aging}

Imitation of aging develops under the influence of an autoimmune or palliative disease. Some of the autoimmune diseases are as follows: Rheumatoid arthritis, Systemic lupus erythematosus (SLE), Multiple sclerosis, Inflammatory bowel disease, Type 1 diabetes mellitus, Guillain-Barre syndrome, chronic inflammatory demyelinating polyneuropathy, Graves' disease, Psoriasis, Hashimoto's thyroiditis vasculitis [35]. The common point of autoimmune diseases is that they cause abnormal immune responses that occur in the body (Shigesi et al., 2019 [36]). The attacks of the immune system threaten the health of the individual. Since such diseases mimic other diseases, their diagnosis is difficult.

Anxiety, depression and neuropsychological effects may occur in the individual when painful symptoms, muscle and joint pain, and skin rashes occur in prominent parts of the body in many organs (Abraham et al., 2020; Conceição et al., 2019; Moustafa et al., 2019 [37-39]). These negative symptoms have a significant cognitive effect on the individual. The source of these pains is often undetectable. Besides, continuous use of drugs such as Corticosteroids, Nonsteroidal anti-inflammatory drugs, Diseasemodifying antirheumatic drugs applied in diseases such as SLE reduces the psychological resilience of individuals (Tollisen et al., 2019; Uhrenholt et al., 2019 [40,41]). Thus, the individual faces the perception of aging. The same situation may emerge in palliative diseases. Continuous treatment can be associated with the weakness, psychological, social and physical declines of the elderly (Mishra et al., 2019 [42]). Both pathological symptoms cause a perception of aging and reveal a situation imitating the aging of the individual. Thus the imitation of aging occurs.

\section{Differences between latent aging and imitation of aging}

The similarities and differences between latent aging and imitation of aging are presented in Table 1.

Table 1: The Similarities and Differences Between Latent Aging and Imitation of Aging.

\begin{tabular}{|c|c|}
\hline Latent Aging & Imitation of Aging \\
\hline $\begin{array}{c}\text { It occurs as a result of perceptual management deficiency and Neuropsy- } \\
\text { chological effects. }\end{array}$ & It occurs as a result of an autoimmune or palliative disease. \\
\hline It is a type of aging. & It is a type of aging. \\
\hline $\begin{array}{l}\text { Effects such as anxiety and depression can generally occur after the percep- } \\
\text { tion of aging. }\end{array}$ & $\begin{array}{l}\text { Effects such as anxiety and depression can generally occur before the } \\
\text { perception of aging. }\end{array}$ \\
\hline It is associated with neuropsychology. & It is associated with neuropsychology. \\
\hline Perceptual process and environmental factors are effective. & Perceptual processes and diseases are effective. \\
\hline Psychological symptoms can be observed. & Pathological symptoms can be observed. \\
\hline It is closely related to psychology and neurology. & It is closely related to rheumatology, immunology, neurology. \\
\hline
\end{tabular}

As can be seen from Table 1, both types of aging are different types as well as their similar aspects. These differences and similarities can be improved by future studies with clinical findings.

\section{Discussion and Conclusion}

Very few studies have been included in the literature on latent aging and imitation of aging. The author Özsungur (2019a) [30], who introduced these concepts, brought this concept to the literature by carrying out a case study on latent aging. Another work of the same author is related to relationship between latent aging and chronic lymphocytic thyroiditis (Özsungur, 2019b [43]). On the other hand, the same author determined that imitation of aging was caused by the effects of SLE (Özsungur, 2020 [44]). All three studies reveal the strong relationship between autoimmune diseases and the perception of old age. Especially, the detection of stress-based phobias created by SLE on spouses is an important finding. In his study on imitation of aging, it was determined that the neuropsychological effects negatively affect the behavior of SLE patients and these behaviors had negative effects on the individual (Özsungur, 2020 [44]).

The psychosocial and psychological aging theories put forward in the literature focus on the decline that occurs with aging. Life stages, attitudes, and behaviors are important determinants in psychology. The negative effects of these determinants on the individual trigger the aging psychologically. However, these theories cannot explain the reasons for the emergence of aging under perceptual and pathological effects. The thoughts, that individuals withdrawing from life will be pushed to loneliness, the needs of the elderly due to the declines regarding aging, are far from revealing the foundations of aging. Latent aging and imitation of aging fill these gaps. Besides, psychological and psychosocial theories related to aging offer suggestions to increase the quality of life and satisfaction of individuals in the face of known aging phenomena. 
However, latent aging and imitation of aging demonstrate the emergence of aging in a pathological and perceptual context by revealing neuropsychological effects. In this respect, both types of aging make important contributions to the field of gerontology.

This study introduces two new types of aging, unlike the types of aging introduced in the literature. It is recommended to investigate these types of aging clinically, which have similarities as well as some basic differences. It is recommended to research especially in the fields of neuropsychology, psychology, and rheumatology. Although it is the strength of the study to introduce the two types of aging introduced in the literature for the first time, it is the limitations of the study that the systematic review is adopted in the study and the results do not contain empirical findings.

\section{Acknowledgement}

None.

\section{Conflict of Interest}

No conflict of interest.

\section{References}

1. LeBlanc K, Campbell K (2020) Prediction, Prevention, Assessment, and Management of Skin Tears in the Aging Population. Therapeutic Dressings and Wound Healing Applications: 43-58.

2. John 0, Fallavollita P (2020) Health Promotion Technology and the Aging Population. In Connected Health in Smart Cities Springer, Cham, pp. 179190.

3. Shah A (2020) Identifying the Unique Needs of the Aging Population. In Geriatric Practice. Springer, Cham, pp. 13-19.

4. Cudjoe TKM, Roth DL, Szanton SL, Wolff JL, Boyd CM, et al. (2020) The epidemiology of social isolation: National health and aging trends study. The Journals of Gerontology: Series B 75(1): 107-113.

5. Tovel H, Carmel S, Raveis VH (2019) Relationships among self-perception of aging, physical functioning, and self-efficacy in late life. The Journals of Gerontology: Series B 74(2): 212-221.

6. Gomez-Moreno C, Verduzco-Aguirre H, Contreras-Garduño S, Perez-deAcha A, Alcalde-Castro J, et al. (2019) Perceptions of aging and ageism among Mexican physicians-in-training. Clinical and Translational Oncology 21(12): 1730-1735.

7. Yin Z, Brasher MS, Kraus VB, Lv Y, Shi X, et al. (2019) Dietary Diversity Was Positively Associated with Psychological Resilience among Elders: A Population-Based Study. Nutrients 11(3): 650.

8. Richerson R, Mead JA, Li W (2019) Evolutionary motives and food behavior modeling in romantic relationships. Journal of Business Research.

9. Jamal SA, Aminudin N, Kausar DR (2019) Family adventure tourism motives and decision-making: A case of whitewater rafting. Journal of Outdoor Recreation and Tourism 25: 10-15.

10. Schüler J, Baumann N, Chasiotis A, Bender M, Baum I (2019) Implicit motives and basic psychological needs. Journal of personality 87(1): 3755.

11. Kagan J (1972) Motives and development. Journal of personality and social psychology 22(1): 51-66.

12. Heckhausen J, Kay JS (2018) Motives, goals, and well-being throughout the lifespan.

13. Sansone C, Harackiewicz JM (2000) Intrinsic and extrinsic motivation: The search for optimal motivation and performance. Elsevier.
14. Porter LW, Lawler EE (1968) What job attitudes tell about motivation (pp. 118-126). Harvard Business Review Reprint Service.

15. Vroom VH (1964) Work and motivation. Victor Harold.

16. Stajkovic AD, Luthans F (2003) Behavioral management and task performance in organizations: conceptual background, meta-analysis, and test of alternative models. Personnel Psychology 56(1): 155-194.

17. Benabou R, Tirole J (2003) Intrinsic and extrinsic motivation. The review of economic studies $970(3)$ : 489-520.

18. Deci EL, Ryan RM (2010) Intrinsic motivation. The corsini encyclopedia of psychology 1-2.

19. Cameron J, Pierce WD (2002) Rewards and intrinsic motivation: Resolving the controversy. Bergin \& Garvey.

20. Duda JL, Chi L, Newton ML, Walling MD (1995) Task and ego orientation and intrinsic motivation in sport. International journal of sport psychology.

21. Kreps DM (1997) Intrinsic motivation and extrinsic incentives. The American Economic Review 87(2): 359-364.

22. Richard M, Christina MF, Deborah LS, Rubio N, Kennon MS (1997) Intrinsic motivation and exercise adherence. Int J Sport Psychol 28(4): 335-354.

23. Hagger MS, Chatzisarantis NL (2007) Intrinsic motivation and selfdetermination in exercise and sport. Human Kinetics.

24. Ajzen I (2002) Perceived behavioral control, self-efficacy, locus of control, and the theory of planned behavior 1 . Journal of applied social psychology 32(4): 665-683.

25. Ajzen I, Madden TJ (1986) Prediction of goal-directed behavior: Attitudes, intentions, and perceived behavioral control. Journal of experimental social psychology 22(5): 453-474.

26. Long S, Newton J (1997) Educating the gut: socio-emotional aspects of the learning organization. Journal of Management Development.

27. Hesp C, Steenbeek HW, Van Geert PL (2019) Socio-emotional concern dynamics in a model of real-time dyadic interaction: parent-child play in autism. Frontiers in psychology 10: 1635.

28. Strong T (2019) Narrative therapy, neuroscience and socio-emotional discourses: Comments. International Journal of Narrative Therapy \& Community Work (3): 64

29. Silva EH, Lawler S, Langbecker D (2019) The effectiveness of mHealth for self-management in improving pain, psychological distress, fatigue, and sleep in cancer survivors: a systematic review. Journal of Cancer Survivorship 13(1): 97-107.

30. Özsungur F (2019a) Latent Aging. Biomedical Journal of Scientific \& Technical Research (BJSTR) 20(4): 15309-15312.

31. Han F, Perrin RJ, Wang Q, Wang Y, Perlmutter JS, et al. (2019) Neuroinflammation and myelin status in Alzheimerhtg's disease, Parkinson's disease, and normal aging brains: A small sample study. Parkinson's Disease.

32. Allegri N, Mennuni S, Rulli E, Vanacore N, Corli O, et al. (2019) Systematic Review and Meta-Analysis on Neuropsychological Effects of Long-Term Use of Opioids in Patients with Chronic Noncancer Pain. Pain Practice 19(3): 328-343

33. Moreno-Gómez AJ, Cejudo J (2019) Effectiveness of a Mindfulness-Based Social-Emotional Learning Program on Psychosocial Adjustment and Neuropsychological Maturity in Kindergarten Children. Mindfulness 10(1): 111-121.

34. Vasan TS, Mathur K, Vyas R (2020) Paradoxical Presentation in A Case of Deep Frontal Lobe Abscess. Archives of Clinical and Medical Case Reports 4: 071-074.

35. Rosenzwajg M, Lorenzon R, Cacoub P, Pham HP, Pitoiset F, et al. (2019) Immunological and clinical effects of low-dose interleukin- 2 across 11 autoimmune diseases in a single, open clinical trial. Annals of the rheumatic diseases 78(2): 209-217. 
36. Shigesi N, Kvaskoff M, Kirtley S, Feng Q, Fang H, et al. (2019) The association between endometriosis and autoimmune diseases: a systematic review and meta-analysis. Human reproduction update 25(4): 486-503.

37. Abraham P, Neel I, Bishay S, Sewell DD (2020) Central Nervous System Systemic Lupus Erythematosus (CNS-SLE) Vasculitis Mimicking Lewy Body Dementia: A Case Report Emphasizing the Role of Imaging with an Analysis of 33 Comparable Cases from the Scientific Literature. Journal of Geriatric Psychiatry and Neurology: 891988720901788.

38. Conceição CTM, Meinão IM, Bombana JA, Sato EI (2019) Psychoanalytic psychotherapy improves quality of life, depression, anxiety and coping in patients with systemic lupus erythematosus: a controlled randomized clinical trial. Advances in Rheumatology 59(1): 4.

39. Moustafa AT, Moazzami M, Engel L, Bangert E, Hassanein M, et al. (2019) Prevalence and metric of depression and anxiety in systemic lupus erythematosus: A systematic review and meta-analysis. In Seminars in arthritis and rheumatism. WB Saunders.

40. Tollisen A, Flatø B, Selvaag AM, Aasland A, Ingebrigtsen T, et al. (2019)
Treatment Satisfaction with and Adherence to Disease-Modifying Antirheumatic Drugs in Adult Patients with Juvenile Idiopathic Arthritis. Arthritis care \& research.

41. Uhrenholt L, Schlemmer A, Hauge EM, Christensen R, Dreyer L, et al. (2019) Dosage reduction and discontinuation of biological diseasemodifying antirheumatic drugs in patients with rheumatoid arthritis, psoriatic arthritis and axial spondyloarthritis: protocol for a pragmatic, randomised controlled trial (the BIOlogical Dose OPTimisation (BIODOPT) trial). BMJ open 9(7): e028517.

42. Mishra S, Beshai S, Wuth A, Refaie N (2019) Risk and protective factors in problem gambling: an examination of psychological resilience. International Gambling Studies 19(2): 241-264.

43. Özsungur F (2019b) A Research on Relationship Between Latent Aging and Chronic Lymphocytic Thyroiditis. Biomedical Journal of Scientific \& Technical Research (BJSTR) 23(5): 17761-17763.

44. Özsungur F (2020) The Psychological Effects of Systemic Lupus Erythematosus: The Imitator of Aging. LymphoSign Journal. 